\title{
ESTIMATION OF THE SPECTRAL DENSITY FUNCTION OF LH2 COMPLEXES FROM THE TEMPERATURE DEPENDENCE OF THE ABSORPTION SPECTRA
}

\author{
O. Vrublevskaja ${ }^{\mathrm{a}}$, V. Urbonienè ${ }^{\mathrm{b}}$, G. Trinkūnas $^{\mathrm{a}}$, L. Valkūnas $^{\mathrm{a}, \mathrm{c}}, \mathrm{A}$. Gall $^{\mathrm{d}}$, and \\ B. Robert ${ }^{\mathrm{d}}$ \\ ${ }^{a}$ Institute of Physics, Savanoriu 231, LT-02300 Vilnius, Lithuania \\ E-mail: Oksana@ar.fi.lt \\ ${ }^{\mathrm{b}}$ Department of General Physics and Spectroscopy, Vilnius University, Saulètekio 9, LT-10222 Vilnius, Lithuania \\ ${ }^{c}$ Department of Theoretical Physics, Vilnius University, Saulètekio 9, LT-10222 Vilnius, Lithuania \\ ${ }^{\mathrm{d}}$ Service de Biophysique des Prote'ines et des Membranes, DBJC/CEA and CNRS/URA2096, C. E. A. Saclay, \\ 91191 Gif-sur-Yvette Cedex, France
}

Received 2 December 2005

\begin{abstract}
The spectral density function of a bacteriochlorophyll molecule in its parametric form describing the exciton coupling to the vibrational bath including the protein and the solvent modes has been determined. This form of spectral density is applied by simulating the temperature dependence of the absorption spectra of the peripheral light harvesting complexes, LH2, of the photosynthetic purple bacterium Rhodobacter sphaeroides inserted into the polyvinyl alcohol film. It has been found that the dynamic characteristics of broadening of both absorption bands of LH2 with the maxima at $850 \mathrm{~nm}$ and $800 \mathrm{~nm}$ are similar to those already obtained for the glycerol solution. The static spectral inhomogeneity of LH2 in the polyvinyl alcohol film, however, is much larger than in the glycerol solution. It is concluded that the LH2 complex in the polyvinyl alcohol film with increase of the temperature is subjected to compression, which is the source of the additional static disorder.
\end{abstract}

Keywords: absorption spectra, Rhodobacter sphaeroides, LH2, spectral density function, temperature dependence, glycerol, polyvinyl alcohol

PACS: 71.35.-y, 71.35 Aa, 87.15 Aa, 87.15-v.

\section{Introduction}

In photosynthesis, solar photons are absorbed by a light-harvesting antenna and are efficiently transported to a reaction centre where charge separation is initiated [1]. Following the elucidation of the structure of the peripheral light-harvesting complex (LH2) of Rhodopseudomonas (Rps.) acidophila [2] defining the relationship between the structure and the spectroscopic properties, studies of the energy transfer dynamics of this complex present a major challenge. The LH2 of Rps. acidophila is arranged as a highly symmetric ring of 9 protein-pigment subunits, each containing 2 helical trans-membrane polypeptides, the $\alpha$-polypeptide on the inner side, and the $\beta$-polypeptide on the outer side of the ring. The hydrophobic terminal of the protein binds a ring of 18 tightly coupled bacteriochlorophyll (Bchl) molecules with a centre-to-centre distance of less than $1 \mathrm{~nm}$ between neighboring pigments. This ring is responsible for the intense absorption at $850 \mathrm{~nm}$
(B850 ring). A second ring of 9 weakly interacting Bchls is located in the polar region of the protein and is largely responsible for the absorption at $800 \mathrm{~nm}$ (B800 ring), consistent with hole-burning data [3], which has indicated that excitonic effects have been unimportant for the B800 ring [4]. However, due to the relatively small distances between the pigments in the B850 rings the interaction between the pigments will play an important role in their spectroscopy. The availability of crystallographic information for LH2 has challenged efforts to infer the electronic properties of these molecules from the exciton theory [5].

Besides the spectroscopic properties of Bchl molecules determined by the close packing in the complex, they are also influenced by interactions with the protein environment. A protein is a complex and flexible medium, its dynamics proceeds on time scales ranging from femtoseconds to hundreds of nanoseconds [6]. Therefore, the pigment-protein interactions can be time dependent. Fluctuations, which occur on a time 
scale longer than the excited state lifetime of the pigment, do not manifest themselves in the optical experiment, i. e., if we consider an ensemble of a large number of molecules, the electronic transition frequencies of the individual pigments will be randomly distributed around a mean value. This results in inhomogeneous broadening, and the corresponding distribution is commonly referred to as the inhomogeneous distribution function (IDF). Since the IDF is related to very slow dynamics in the surrounding protein, the term of static disorder is also used. Rapid fluctuations, however, are related to vibrations of the pigments and the surrounding protein and define the homogeneous line shape. All basic spectroscopic features can be understood on the basis of a model that includes both the intrinsic pigment site energy disorder and the exitonic coupling between the pigments.

With reference to this information comparative analysis of the experimentally obtained and numerically modelled exitonic absorption spectra of the LH2 complexes has been performed. The LH2 absorption spectra of the Rhodobacter (Rb.) sphaeroides in Tris[hydroxymethyl]aminomethane (Tris. Cl.)-glycerol solution have been measured in a wide temperature range in order to determine the spectral density function (SDF) from modelling results and fitting the experimental data to characterize the role of protein in the exciton-nuclear bath interaction [7]. The LH2 from $R b$. sphaeroides exhibits the same architecture as the LH2 complex from Rps. acidophila [8,9], and the established coordinates and orientations of the transition dipole momenta of the unit vectors $[2,10]$ were used for calculations. The discrepancies between the modelled and experimentally measured absorption spectra at higher temperatures including the observed extra band broadening and the band shift have been disclosed. This has been rationalized by the temperature dependence of the static dielectric constant of the glycerol/ water solution [7]. It has been shown by Yu [11] that the drastic change of the dielectric constant of the solvent $(7<\varepsilon<60)$ takes place between around $200 \mathrm{~K}$ and the room temperature, covering the whole range in which the glycerol/water solution remains in the liquid phase. In order to avoid the variation of the dielectric constant with temperature observed in the glycerol solution, in this work the absorption spectra of LH2 have been measured in the polyvinyl alcohol (PVA) films $(\varepsilon<2)$. By comparing the obtained SDF to that found earlier for the glycerol solution we discriminate between vibrational modes of the protein, the solvent, and the molecule coupled to the excitons.

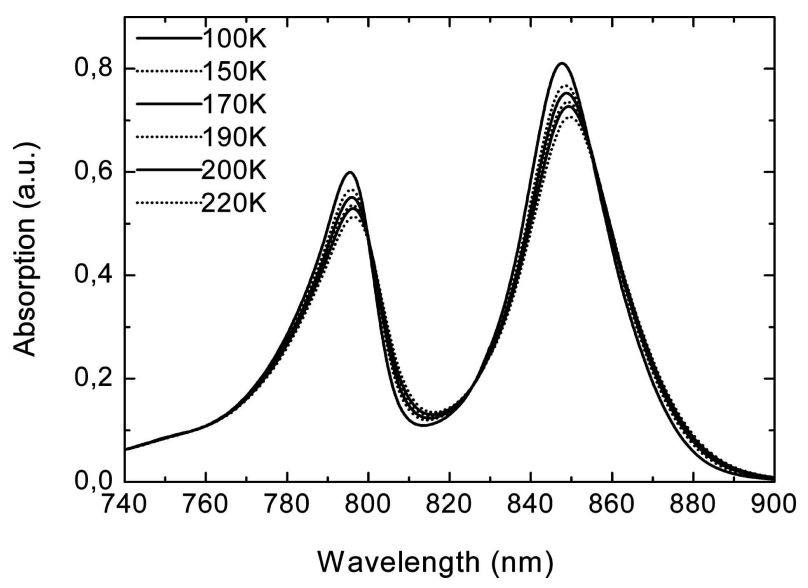

Fig. 1. Absorption spectra of purified LH2 from $R b$. sphaeroides for PVA in the 100-220 K temperature range.

\section{Materials and methods}

The LH2 complexes of $R b$. sphaeroides 2.4 .1 were isolated according to the procedure described earlier [7]. For the absorption studies, thin polymer films were prepared by adding $10 \mu \mathrm{L} \mathrm{LH} 2$ to a $0.03 \mathrm{ml}$ of solution of polyvinyl alcohol - water (distil water $\mathrm{pH} 8.0$ ), then a thin layer of solution was coated on a substrate. By dropping $0.031 \mathrm{ml}$ of solution on the substrate and leaving it to volatilize in the gas nitrogen box for 3 hours, the estimated thickness was $0.182 \mathrm{~mm}$. The complete temperature cycle was measured by progressively decreasing the temperature. The $100-200 \mathrm{~K}$ range was also achieved by slowly raising the temperature. In order to ensure the equilibrium between the sample and the helium bath, the sample was stabilized at each measured temperature for at least 15 minutes.

Electronic absorption spectra were collected using a Varian Cary E5 double-beam scanning spectrophotometer. Temperature of the samples was precisely maintained by a Helium bath cryostat (Maico Metriks, Tartu, Estonia).

Figure 1 shows the evolution of the near infrared (740-900 nm) electronic absorption spectra of the LH2 complexes from $R b$. sphaeroides in PVA in the 100$220 \mathrm{~K}$ temperature range. It is apparent that two major electronic transitions located at 800 and $850 \mathrm{~nm}$ contribute to these spectra. Raising the temperature simultaneously determines the broadening of both these transitions, accompanied by small shifts of their position to the red side of the spectrum.

\section{Model}

The absorption spectrum of the molecular aggregate can be defined by using the Frenkel exciton model [12]. 
The line shape function of the exciton transition spectrum is determined by the interaction between the exciton and the bath, the latter being well characterized by a set of harmonic oscillators (vibrations / phonons). Dynamic theory of the absorption line shape was formulated by Lax in 1952 [13] and it is presented in detail in monographs of Mukamel [14], van Amerongen et al. [5], Osadko [15], May and Kühn [16] as well as in a number of papers devoted to linear and nonlinear spectroscopic applications [17-19]. Since we will use the parametric form of the SDF, we apply the simplest version of this theory taking into account the diagonal part of the dynamics only, and explicitly discriminating against static diagonal disorder [17]:

$$
\begin{aligned}
H= & \sum_{n=1}^{N}\left(\varepsilon_{n}+q_{n}^{(c)}\right)|n\rangle\langle n| \\
& +\sum_{n, m=1(n \neq m)}^{N} t_{n m}|n\rangle\langle m|+H_{\mathrm{ph}},
\end{aligned}
$$

where $|n\rangle$ and $\langle n|$ represent ket and bra vectors, respectively, of the molecular excitation localized on the $n$th molecule of the B850 aggregate. Due to the ensemble of the LH2 complexes considered, the excitation energy $\varepsilon_{n}$ is assumed to be a Gaussian random variable with mean $\varepsilon_{0}$ and the full width at half maximum (FWHM) $\Gamma^{\text {inh }}$ of the IDF:

$$
\begin{aligned}
f_{\operatorname{inh}}\left(\varepsilon_{n}\right)= & \frac{2}{\Gamma^{\operatorname{inh}}} \sqrt{\frac{\ln (2)}{\pi}} \\
& \times \exp \left(-\frac{4 \ln (2)\left(\varepsilon_{n}-\varepsilon_{0}\right)^{2}}{\left(\Gamma^{\mathrm{inh}}\right)^{2}}\right) .
\end{aligned}
$$

Matrix elements $t_{n m}$ denote the interpigment dipoledipole coupling energies $\left(V \equiv \max \left(t_{n m}\right)\right)$ between the pigments on the sites $n$ and $m$. They are calculated from the Rps. acidophila LH2 structure file [2]. The $q_{n}^{(c)}$ represents the local collective bath coordinates related to molecule $n$. All relevant information about the dynamic exciton interaction with the bath is contained in the following SDF [14]:

$$
C_{n, n}(\omega)=\frac{\mathrm{i}}{2} \int_{-\infty}^{\infty} \mathrm{d} t \exp (\mathrm{i} \omega t)\left\langle\left[q_{n}^{(c)}(t), q_{n}^{(c)}(0)\right]\right\rangle,
$$

where the bath average and time evolution are taken in respect of the free phonon Hamiltonian $H_{\mathrm{ph}}$ [14]. Eq. (3) admits that the baths for all molecules have the

same spectral density and that the baths acting on different molecules are uncorrelated.

Introducing exciton states

$$
|k\rangle=\sum_{n=1}^{N} \varphi_{k n}|n\rangle,
$$

where $\varphi_{k n}$ is the coefficient describing the participation value of the $n$th excited molecule in the $k$ th exciton state, the Hamiltonian given by Eq. (1) is obtained in its diagonal form:

$$
H=\sum_{k=1}^{N}\left(E_{k}+q_{k}^{(c)}\right)|k\rangle\langle k|+H_{\mathrm{ph}},
$$

where the exciton energy $E_{k}$, the collective nuclear coordinate $q_{k}^{(c)}$, as well as the $\operatorname{SDF} C_{k, k}(\omega)$ relate to the site characteristics as follows [17]:

$$
\begin{aligned}
& E_{k}=\sum_{n=1}^{N}\left|\varphi_{k n}\right|^{2} \varepsilon_{n}, \quad q_{k}^{(c)}=\sum_{n=1}^{N}\left|\varphi_{k n}\right|^{2} q_{n}^{(c)}, \\
& C_{k, k}(\omega)=\sum_{n=1}^{N}\left|\varphi_{k n}\right|^{4} C_{n, n}(\omega) .
\end{aligned}
$$

The polarization operator representing linear coupling of the aggregate with the optical field can be given by

$$
\mathbf{P}=\sum_{k} \boldsymbol{\mu}_{k}(|k\rangle+\langle k|),
$$

where $\boldsymbol{\mu}_{k}=\sum_{n} \boldsymbol{\mu}_{n} \varphi_{k n}$ and $\boldsymbol{\mu}_{n}$ are transition dipole moments related to the exciton state $k$ and to the $n$th molecule, respectively.

With these data at hand, the cumulant expansion technique provides the expression for the aggregate absorption spectrum [14, 18]

$$
\begin{aligned}
& \sigma_{a}(\omega)=\frac{1}{2 \pi} \\
& \times\left\langle\sum_{k} \boldsymbol{\mu}_{k}^{2} \operatorname{Re}\left[\int_{0}^{\infty} \mathrm{d} t \mathrm{e}^{\mathrm{i}\left(\omega-E_{k}\right) t-g_{k}(t, T)-\gamma t}\right]\right\rangle_{\substack{\text { static } \\
\text { disorder }}},
\end{aligned}
$$

where $\gamma$ is the mean intraband exciton relaxation time, and the spectral broadening function $g_{k}(t)$ is derived as follows:

$$
\begin{aligned}
& g_{k}(t, T)=\int_{-\infty}^{\infty} \mathrm{d} \omega \frac{C_{k, k}(\omega)}{2 \pi \omega^{2}} \\
& \times\left\{\operatorname{coth}\left(\frac{\hbar \omega}{2 k_{\mathrm{B}} T}\right)[1-\cos (\omega t)]-\mathrm{i}[\sin (\omega t)-\omega t]\right\} .
\end{aligned}
$$


The exciton relaxation time deduced from ultrafast spectroscopies is about $50 \mathrm{fs}$ [20], which corresponds to the phenomenological homogeneous broadening constant $\gamma \approx 100 \mathrm{~cm}^{-1}$. When applied to the absorption spectra simulations at various temperatures, this strong broadening results in an unrealistically small static disorder. It is well established that $\Gamma^{\text {inh }} \geq V$ for LH2 complexes [5]. Therefore, $\gamma=50 \mathrm{~cm}^{-1}$ has been introduced to take into account the exciton intraband relaxation.

It should be noted that, when dropping the sum over excitonic states $k$, Eq. (8) takes the form of the absorption spectrum of a single molecule embedded into the phonon bath characterized by the SDF: $C_{k, k}(\omega) \equiv$ $C(\omega)$. From the SDF, the excited Bchl reorganization energy, which characterizes the exciton-bath coupling, can be obtained straightaway [14]:

$$
\lambda=\frac{1}{\pi} \int_{0}^{\infty} \mathrm{d} \omega \frac{C(\omega)}{\omega} .
$$

Recently, using the fluorescence line narrowing (FLN) experiments by Creemers et al. [21], Renger and Marcus [22] determined the SDF in a parametric form for the so-called B777 subunit. This unit is separated from the proximal light-harvesting complex LH1 of the photosynthetic purple bacteria by using the dissociation and contains a single Bchl molecule bound to an $\alpha$-helix [23]. Therefore, it is characterized solely by the pigment-bath interaction. The obtained SDF can be approximated and expressed in a more convenient elementary function form [19]

$$
C(\omega)=a \omega \exp \left(-\frac{\omega}{\omega_{1}}\right)+b \frac{\omega^{2}}{\omega_{2}} \exp \left(-\frac{\omega}{\omega_{2}}\right)
$$

Four variable parameters $a, b, \omega_{1}$, and $\omega_{2}$ have no clear physical meaning. Nevertheless, as the integral (see Eq. (10)) of the SDF defined by Eq. (11) gives the reorganization energy $\lambda$, two exponent terms can be interpreted as contributing from two distinct spectral distribution modes.

By applying the approximate series expansion for $\operatorname{coth}\left[\hbar \omega /\left(2 k_{\mathrm{B}} T\right)\right]$, analytical integration for the broadening function, Eq. (9), can be then easily performed giving algebraic expressions [24]. Therefore, the form of Eq. (11) has been used for further simulations.
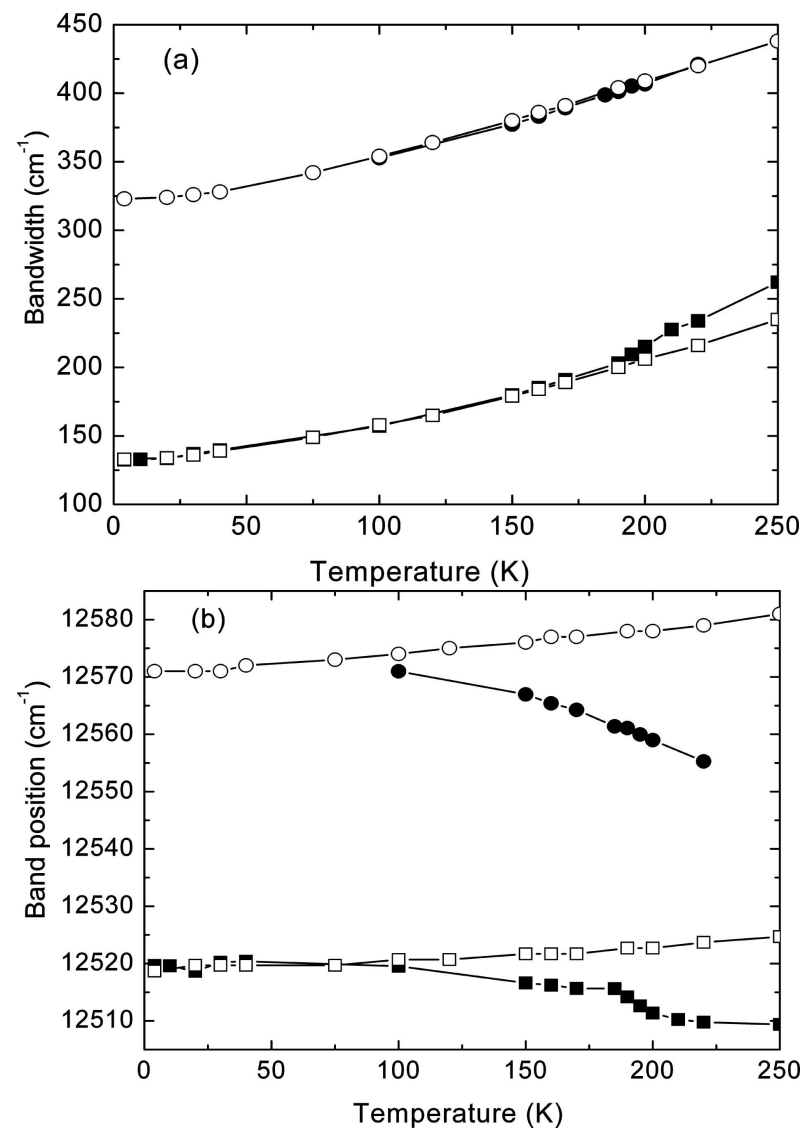

Fig. 2. Measured (solid symbols) and calculated (open symbols) temperature dependences of the (a) FWHM and (b) maximum position of the B800 absorption spectra in PVA (circles) and in Tris. Cl.-glycerol (squares). SDF parameters are presented in Table 1.

\section{Comparison of modelling with experimental data}

The series of the LH2 absorption spectra measured at different temperatures are presented in Fig.1. The excitons in $\mathrm{B} 850$ and $\mathrm{B} 800$ rings were considered as isolated, so the B850 and B800 spectra were additive and could be calculated independently, although the coupling between both exciton subsystems may be important to the excitation transfer [25]. This hypothesis is reasonable since the B850 excitation has very little influence on the B800 absorption band [26].

Modelling of the B800 absorption versus temperature was performed by taking the parametric SDF form (Eq. (11)) into account. The spectra were simulated by adjusting all four parameters of the SDF and the FWHM of IDF, namely, $a, b, \omega_{1}, \omega_{2}$, and $\Gamma^{\text {inh }}$. The least deviation of the courses of the FWHM of the absorption spectrum versus temperature for the measured and simulated data was used as the criterion of goodness of the SDF as it was done while simulating the experimental data of LH2 in the glycerol buffer [7]. A 
very good fit for the FWHM dependence on temperature is obtained as shown in Fig. 2(a). The analogous fit for the data corresponding to the LH2 in glycerol [7] is presented for reference. It can be noticed that the deviations characteristic of the glycerol solution at higher temperatures are absent in case of PVA indeed. The best fit parameters for the SDF were found to be close to those obtained for the absorption spectra in the glycerol buffer, except for the FWHM of IDF that appeared to be much larger (see Table 1). However, the differences between the modelled and experimental FWHM courses for the B800 band maximum position at higher temperatures are similar for both solutions (see Fig. 2(b)). In spite of the negligible absolute deviations, which are close to measurement errors, the pronounced trend of the red shift of the B800 band with temperature is evident.

Notwithstanding the well reproduced FWHM dependence on temperature, the simulated shape of the B800 band differs from the experimental one (see Fig. 3 for the comparison at $100 \mathrm{~K}$ ). It is mainly due to the asymmetric B800 band broadening with the wellexpressed shoulder at the higher energy side, which cannot be reproduced properly within the given model. The differences between the experimental and simulated spectra in the B800 band region suggest the absorption subband at $780 \mathrm{~nm}$. It could be attributed to the uncoupled bacteriochlorophylls [27]. The possibility of the upper excitonic subband, hidden under the B800 band in case of the glycerol solution, also cannot be ruled out. In the latter case it would mean that the LH2 aggregate in PVA is subjected to compression, which results in an increase of the interpigment dipoledipole coupling.

For the B850 band, which is related to more closely packed Bchl molecules, the excitonic coupling has been taken into account. For the linear exciton-phonon interaction the first moment of the excitonic absorption line shape does not vary with temperature, while the second moment is temperature dependent [28]. Therefore, the parameters of the SDF as well as $\Gamma^{\mathrm{inh}}$ for the B850 absorption band have been determined by simulating the temperature dependence of the experimentally measured FWHM of the B850 band. The best fit of the FWHM versus temperature is displayed in Fig. 4 (circles) together with the comparison of the experimental and modelled dependences of the maximum position of this band. The simulated curve for the FWHM of the band matches the experimental data very well in the whole temperature range (100-220 K). The course of the experimental band maximum, in contrast to the

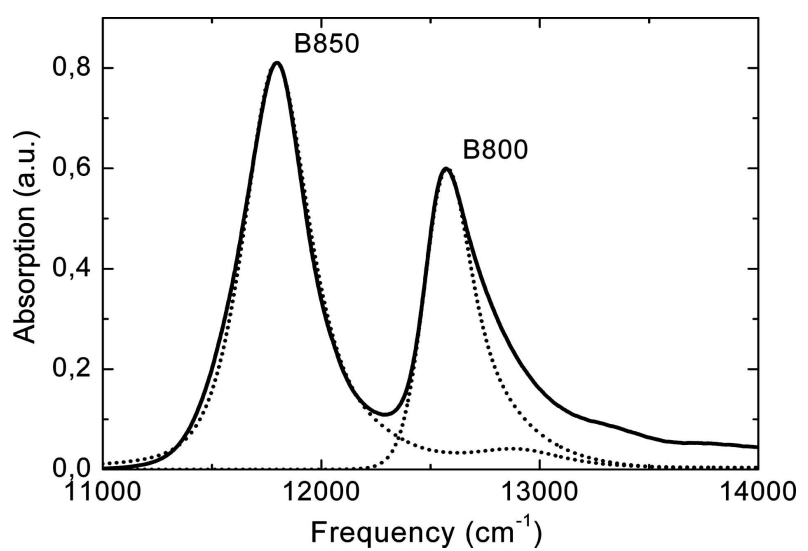

Fig. 3. Experimental (solid line) and modelled B850 and B800 (dotted lines) absorption spectra of LH2 at $100 \mathrm{~K}$. Parameters used for calculation are presented in Table 1. Experimental spectra were obtained for LH2 in PVA.
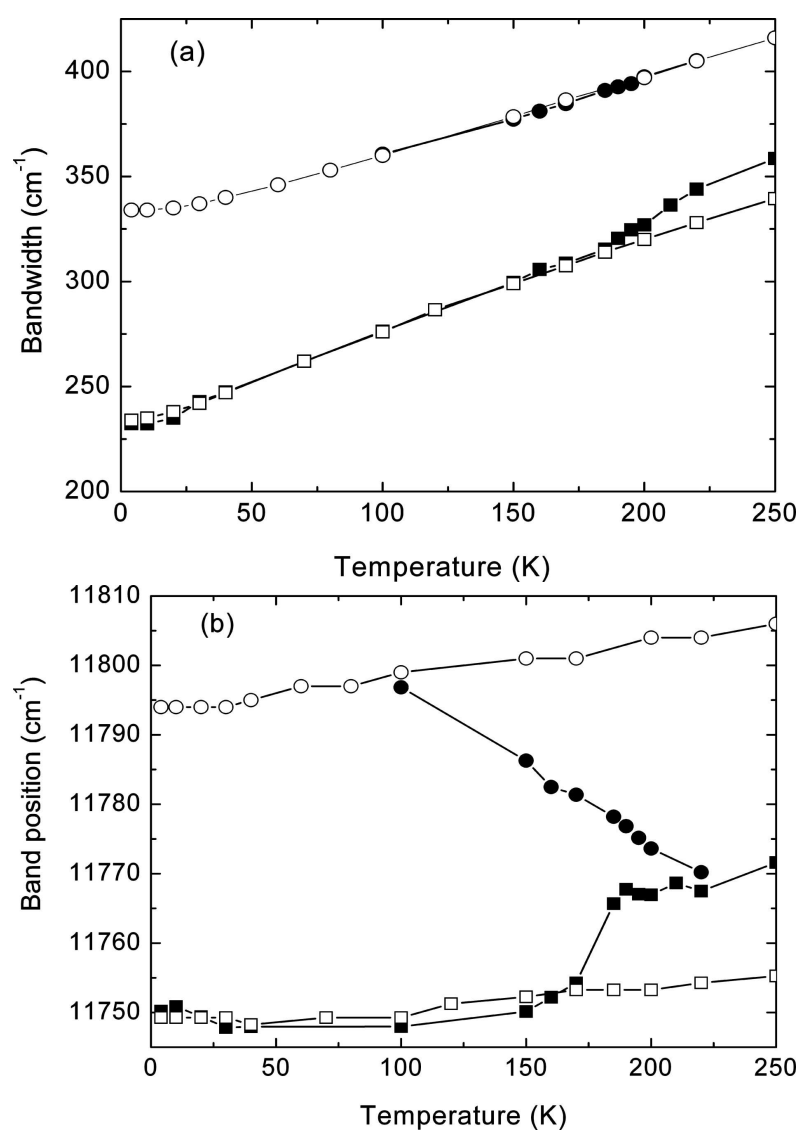

Fig. 4. Measured (solid symbols) and calculated (open symbols) temperature dependences of the (a) FWHM and (b) maximum position of the B850 absorption spectra in PVA (circles) and in Tris. Cl.-glycerol (squares). SDF parameters are presented in Table 1.

simulated spectra, shows a red shift at higher temperatures. This trend is opposite to the one observed for the glycerol solution [7]. 
Table 1. Optimal SDF and IDF parameters and derived characterstics (Eqs. (10), (11)). $\Gamma^{\mathrm{inh}}$ is the FWHM of IDF; $a$ and $b$ are linear parameters of the SDF; $\omega_{1}$ and $\omega_{2}$ are characteristic frequencies of the first and second exponent of the SDF; $\lambda$ is the reorganization energy (half of the Stokes shift) of the Bchl molecule.

\begin{tabular}{lcccccc}
\hline \multicolumn{1}{c}{ Band } & $\Gamma^{\mathrm{inh}}, \mathrm{cm}^{-1}$ & $a$ & $b$ & $\omega_{1}, \mathrm{~cm}^{-1}$ & $\omega_{2}, \mathrm{~cm}^{-1}$ & $\lambda, \mathrm{cm}^{-1}$ \\
\hline B800 in glycerol & 120 & 0.130 & 0.583 & 10 & 190 & 112 \\
B800 in PVA & 200 & 0.156 & 0.701 & 10 & 109 & 78 \\
B850 in glycerol & 360 & 4.911 & 5.696 & 10 & 30 & 220 \\
B850 in PVA & 492 & 2.981 & 3.458 & 10 & 55 & 220 \\
\hline
\end{tabular}

\section{Discussion}

The SDFs determined for the B800 and B850 bands of the LH2 complex in PVA were found to be similar to those obtained for these bands in the glycerol / buffer solution [7] (see in Table 1). The obtained reorganization energy $\lambda$ (Table 1) corresponding to the half of the Stokes shift has been found to be somewhat smaller for the B800 Bchl molecules in PVA than for the glycerol/buffer solution; that compares well with the experimental data [29]. The reorganization energy for B850 is approximately two times larger than that for B800 and is similar to the value found by Rutkauskas et al. [30] and Freiberg et al. [31] when simulating the fluorescence spectra. It indicates that the exitonphonon coupling for the bacteriochlorophylls in B850 is much stronger than in B800 aggregates. However, the ratio $\lambda / 2 V$ that corresponds to the actual strength of the exciton-phonon coupling, gives 0.36 for B850 band in PVA indicating a weak coupling case similar to the ratio obtained for the glycerol solution [7].

It is important to note that in order to fit the maximum course of the B850 absorption band with temperature the nearest-neighbor dipole-dipole coupling has to be reduced from $342 \mathrm{~cm}^{-1}$ used for the glycerol / buffer solution [7] to $303 \mathrm{~cm}^{-1}$. The origin of diminishing of the excitonic coupling is not clear. However, it might be the result of stretching of the LH2 complexes in PVA during the film preparation. The overall blue shift could be related to the less polar PVA environment of $\mathrm{LH} 2$ as compared to the case of the glycerol environment.

Positions of the band maximum of the LH2 absorption bands depending on the temperature in PVA (see solid circles in Figs. 2 and 4) show untypical trend of the red shift above $100 \mathrm{~K}$, which is in contrast with the simulated spectra. The cause for this behaviour is not clear yet. However, the overall stronger broadening of the absorption spectra in PVA at all temperatures suggests that the LH2 complexes are dispersed in PVA and experience different local stretching / squeezing due to PVA expansion with temperature. Therefore, the cavities occupied by LH2 might be subjected to the increas- ing pressure. The strong broadening and the red shift of both B800 and B850 bands with the hydrostatic pressure are well known from the earlier studies $[32,33]$. It should be noted that the $\mathrm{B} 800$ band observed in this work takes the asymmetric shape (see Fig. 3) and is similar to the characteristic shape of B800 under pressure [32,33].

The LH2 stretching / squeezing effect in PVA has not been taken into account when simulating the spectra. Therefore, they show a typically minor blue shift of the simulated spectra as manifestation of the vibrational sidebands developing with temperature.

The above-presented data of the temperature dependences of the absorption spectra show that the dispersion of LH2 complexes in PVA has a crucial effect on the spectral band shapes. Conclusions concerning the protein influence on the absorption spectra can be formulated after further careful analysis of the effects discussed above.

\section{Acknowledgements}

This research was supported by the Lithuanian State Science and Studies Foundation and by the Gilibert project in support of the French-Lithuanian scientific collaboration. V. U. also acknowledges the Marie Curie Host fellowship Programm, contract No. HPMT-CT2000-00162.

\section{References}

[1] G.R. Fleming and R. van Grondelle, Femtosecond spectroscopy of photosynthetic light-harvesting systems, Curr. Opinion Struct. Biol. 7, 738-748 (1997).

[2] G. McDermott, S.M. Prince, A.A. Freer, A.M. Hawthornthwaite-Lawless, M.Z. Papiz, R.J. Cogdell, and N.W. Isaacs, Crystal structure of an integral membrane light-harvesting complex from photosynthetic bacteria, Nature 374, 517-521 (1995). 
[3] V. Zazubovich, R. Jankowiak, and G.J. Small, On B800-B800 energy transfer in the LH2 complex of purple bacteria, J. Lumin. 98, 123-129 (2002).

[4] X. Hu, T. Ritz, A. Damjanovic, and K. Schulten, Pigment organization and transfer of electronic excitation in the photosynthetic unit of purple bacteria, J. Phys. Chem. B 101 (19), 3854-3871 (1997).

[5] H. van Amerongen, L. Valkunas, and R. van Grondelle, Photosynthetic Excitons (World Scientific, Singapore, 2000).

[6] F.G. Parak, Physical aspects of protein dynamics, Rep. Prog. Phys. 66, 103-129 (2003).

[7] V. Urboniene, O. Vrublevskaja, A. Gall, G. Trinkunas, B. Robert, and L. Valkunas, Temperature broadening of LH2 absorption in glycerol solution, Photosynthesis Res. 86 (1-2), 49-59 (2005).

[8] T. Walz, S.J. Jamieson, C.M. Bowers, P.A. Bullough, and C.N. Hunter, Projection structures of three photosynthetic complexes from Rhodobacter sphaeroides: LH2 at $6 \AA$, LH1 and RC-LH1 at $25 \AA$, J. Mol. Biol. 282 (4), 833-845 (1998).

[9] P. Braun, A.P. Végh, M. von Jan, B. Strohmann, C.N. Hunter, B. Robert, and H. Scheer, Identification of intramembrane hydrogen bonding between $13^{1}$ keto group of bacteriochlorophyll and serine residue $\alpha 27$ in the LH2 light-harvesting complex, Biochim. Biophys. Acta 1607(1), 19-26 (2003).

[10] A. Freer, S. Prince, K. Sauer, M. Papiz, A. Hawthornthwaite-Lawless, G. McDermott, R. Cogdell, and N.W. Isaacs, Pigment-pigment interactions and energy transfer in the antenna complex of the photosynthetic bacterium Rhodopseudomonas acidophila, Structure 4(4), 449-462 (1996).

[11] I. Yu, Electrodeless measurement of RF dielectric constant and loss, Meas. Sci. Technol. 4, 344-348 (1993).

[12] A.S. Davydov, Theory of Molecular Excitons (Plenum Press, New York, 1971).

[13] M. Lax, The Franck-Condon principle and its application to crystals, J. Chem. Phys. 20, 1752-1760 (1952).

[14] S. Mukamel, Principles of Nonlinear Optical Spectroscopy (Oxford, New York, 1995).

[15] I.S. Osadko, Selective Spectroscopy of Single Molecules (Springer, Berlin-New York, 2003).

[16] V. May and O. Kühn, Charge and Energy Transfer Dynamics in Molecular Systems (Wiley-VCH, Berlin, 2004).

[17] T. Meier, V. Chernyak, and S. Mukamel, Femtosecond phonon echoes in molecular aggregates, J. Chem. Phys. 107(21), 8759-8780 (1997).

[18] W.M. Zhang, T. Meier, V. Chernyak, and S. Mukamel, Simulation of three-pulse-echo and fluorescence depolarization in photosynthetic aggregates, Phil. Trans. R. Soc. London, Ser. A 356, 405-419 (1998).

[19] S. Jang and R.J. Silbey, Single complex line shapes of the B850 band of LH2, J. Chem. Phys. 118(20), 93249336 (2003).
[20] L.D. Book, A.E. Ostafin, N. Ponomarenko, J.R. Norris, and N.F. Scherer, Exciton delocalization and initial dephasing dynamics of purple bacterial LH2, J. Phys. Chem. B 104(34), 8295-8307 (2000).

[21] T.M.H. Creemers, C.A. de Caro, R.W. Visschers, R. van Grondelle, and S. Völker, Spectral hole burning and fluorescence line narrowing in subunits of the light-harvesting complex LH1 of purple bacteria, J. Phys. Chem. B 103(44), 9770-9776 (1999).

[22] T. Renger and R.A. Marcus, On the relation of protein dynamics and exciton relaxation in pigment-protein complexes: An estimation of the spectral density and a theory for the calculation of optical spectra, J. Chem. Phys. 116(22), 9997-10019 (2002).

[23] J.N. Sturgis and B. Robert, Thermodynamics of membrane polypeptide oligomerization in light-harvesting complexes and associated structural changes, J. Mol. Biol. 238(3), 445-454 (1994).

[24] S. Jang, J. Cao, and R.J. Silbey, On the temperature dependence of molecular line shapes due to linearly coupled phonon bands, J. Phys. Chem. B 106(3), 83138317 (2002).

[25] G.D. Scholes, I.R. Gould, R.J. Cogdell, and G.R. Fleming, Ab initio molecular orbital calculations of electronic couplings in the LH2 bacterial lightharvesting complex of Rps. acidophila, J. Phys. Chem. B 103, 2543-2553 (1999).

[26] A. Freiberg, J.A. Jackson, S. Lin, and N.W. Woodbury, Subpicosecond pump-supercontinuum probe spectroscopy of LH2 photosynthetic antenna proteins at low temperature, J. Phys. Chem. A 102(23), 43724380 (1998).

[27] M. Rätsep, C.N. Hunter, J.D. Olsen, and A. Freiberg, Band structure and local dynamics of excitons in bacterial light-harvesting complexes revealed by spectrally selective spectroscopy, Photosynthesis Res. 86(1-2), 37-48 (2005).

[28] A.S. Davydov, Solid-State Theory (Nauka, Moscow, 1986) [in Russian].

[29] R. van Grondelle, H.J.M. Kramer, and C.P. Rijgersberg, Energy transfer in the B800-850-carotenoid light-harvesting complex of various mutants of Rhodopseudomonas sphaeroides and of Rhodopseudomonas capsulata, Biochim. Biophys. Acta 682, 208-215 (1982).

[30] D. Rutkauskas, V. Novoderezhkin, R.J. Cogdell, and R. van Grondelle, Fluorescence spectroscopy of conformational changes of single LH2 complexes, Biophys. J. 88(1), 422-435 (2005).

[31] A. Freiberg, M. Rätsep, K. Timpmann, G. Trinkunas, and N. W. Woodbury, Self-trapped excitons in LH2 antenna complexes between $5 \mathrm{~K}$ and ambient temperature. J. Phys. Chem. B 107, 11510-11519 (2003).

[32] K. Timpmann, A. Ellervee, T. Pullerits, R. Ruus, V. Sundstrom, and A. Freiberg, Short-range exciton couplings in $\mathrm{LH} 2$ photosynthetic antenna pro- 
teins studied by high hydrostatic pressure absorption spectroscopy, J. Phys. Chem. B 105(35), 8436-8444 (2001).

[33] A. Gall, A. Ellervee, J.N. Sturgis, N.J. Fraser, R.J. Cogdell, A. Freiberg, and B. Robert, Mem- brane protein stability: High pressure effects on the structure and chromophore-binding properties of the light-harvesting complex LH2, Biochemistry 42(44), 13019-13026 (2003).

\title{
LH2 KOMPLEKSU SPEKTRINĖS TANKIO FUNKCIJOS NUSTATYMAS, REMIANTIS SUGERTIES SPEKTRŲ TEMPERATŪRINIŲ PRIKLAUSOMYBIŲ MATAVIMAIS
}

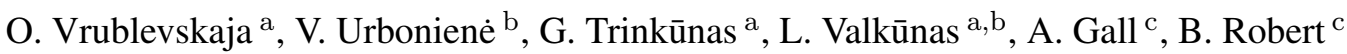 \\ ${ }^{a}$ Fizikos institutas, Vilnius, Lietuva \\ ${ }^{\mathrm{b}}$ Vilniaus universitetas, Vilnius, Lietuva \\ ${ }^{c}$ Service de Biophysique des Prote'ines et des Membranes, C.E.A. Saclay, Prancūzija
}

\section{Santrauka}

Nustatyta bakteriochlorofilo molekulès spektrinès tankio funkcijos, aprašančios eksitonų sąveiką su visomis bakteriochlorofilo molekulių, baltymo ir tirpiklio vibracinėmis modomis, parametrinė forma. Ši forma pritaikyta periferiniu šviesą surenkančių kompleksu LH2, išskirtu iš Rhodobacter sphaeroides fotosintetinančiu bakterijų, esančiu polivinilalkoholio plèvelèje, sugerties spektru temperatūrinèms priklausomybèms modeliuoti. Rasta, kad abieju
LH2 sugerties juostų su maksimumais ties 850 ir $800 \mathrm{~nm}$ išplitimo dinaminès savybès panašios i atitinkamas glicerolio buferio savybes. Tačiau polivinilalkoholio plèveleje LH2 spektrinis išplitimas dèl statinès netvarkos yra daug didesnis negu glicerolio buferyje. Galima daryti išvadą, kad polivinilalkoholio plèvelejje LH2 kompleksai kylant temperatūrai yra suspaudžiami, o tai lemia papildomą statinę netvarką. 